\title{
Stable Planar Six- $\pi$-Electron Six-Membered N-Heterocyclic Carbenes with Tunable Electronic Properties
}

\author{
Carsten Präsang, Bruno Donnadieu, and Guy Bertrand \\ UCR-CNRS Joint Research Chemistry Laboratory (UMR 2282), Department of Chemistry, \\ University of California, Riverside, California 92521-0403
}

The last 15 years have seen tremendous advances in carbene chemistry that transformed these electron-deficient species ${ }^{1}$ into the realm of isolable compounds ${ }^{2}$ and powerful tools for synthetic chemists. Despite the existence of several families of stable carbenes, it has to be recognized that, so far, only the cyclic diamino carbenes (NHCs) have found numerous applications. NHCs are excellent catalysts on their own, ${ }^{3}$ and there is increasing experimental evidence that NHC-metal catalysts surpass their phosphine-based counterparts in both activity and scope of application. ${ }^{4}$ Having said that, it is clear that the success of phosphorus- and nitrogen-based ligands was, and is still, due to their enormous structural diversity. So far, the structures of stable NHCs available have been largely restricted to saturated and unsaturated five-membered heterocycles $\mathbf{A}^{5}$ and $\mathbf{B}^{, 6}$ the only exceptions being carbenes $\mathbf{C}-\mathbf{F}^{7}$ (Scheme 1). Moreover, it has been shown that free acyclic carbenes, including diamino carbenes, ${ }^{8}$ are far more fragile than NHCs and are poor ligands for transition metal complexes. ${ }^{9}$ Therefore, it is of interest to design new stable cyclic diamino carbenes possessing different scaffolds and electronic structures.

Borazines G, discovered by Stock 10 in 1926, and currently used for the fabrication of advanced material based on boron nitride, ${ }^{11}$ constitute a family of extremely stable heterocycles. Because they are isoelectronic to benzene, they are often regarded as the archetypical example of an inorganic aromatic compound, although the extent of aromaticity of $\mathbf{G}$ in relation to that of benzene is still debated. ${ }^{12}$ Since boranes are isoelectronic with both carbocations and carbenes, it was reasonable to believe that the mixed organic/inorganic heterocycles $\mathbf{H}$ and $\mathbf{I}$ would be quite stable. Importantly, the lone pairs of the nitrogen atoms, adjacent to the carbene center of $\mathbf{I}$, can interact both with the carbene and with the boron vacant orbitals. Varying the nature of the substituents at the boron centers, and thus modifying their Lewis acidity, should allow for the preparation of carbenes with quasi-identical steric demands, but different electronic properties; this would permit a better understanding of the factors governing the catalytic activity of the ensuing complexes.

Derivative $\mathbf{4} \mathbf{a}^{13}$ was obtained in one step (83\% yield) by treatment of $\mathrm{N}$-silylated formamidine 1 with compound $\mathbf{2}$. To replace the amino group at the boron centers by a weaker $\pi$-donor substituent, a different synthetic approach has been designed; indeed, 1,3-dibromo-1,3diboranes of type $\mathbf{2}$ are only readily available with amino substituents. Derivative $\mathbf{3}$ was prepared according to a known procedure. ${ }^{14}$ Then, deprotonation with $n$-butyllithium and subsequent treatment with the desired dibromoborane afforded derivatives $\mathbf{4 b}, \mathbf{c}^{13}$ in 74 and $71 \%$ yield, respectively. The influence of the nature of the boron substituents is clearly apparent in the ${ }^{1} \mathrm{H}$ NMR chemical shift of the iminium proton: 8.8 (4a), 9.4 (4b), 9.7 (4c) ppm. Addition at $-78{ }^{\circ} \mathrm{C}$ of lithium tetramethyl piperidine to a THF solution of derivatives $4 \mathbf{a}-\mathbf{c}$ cleanly

E-mail: gbertran@mail.ucr.edu.. 
afforded carbenes $\mathbf{5 a}-\mathbf{c}$, which were isolated after recrystallization from hexanes as lightyellow crystals ${ }^{13}$ (Scheme 2).

Both types of heterocycles $\mathbf{4}$ and $\mathbf{5}$ are perfectly stable at room temperature, in solution, and in the solid state. The single-crystal X-ray diffraction study 15 of $\mathbf{4 c}$ and $\mathbf{5 c}$ (Figure 1) reveals, in both cases, the expected planar six-membered ring skeleton with a propeller-like arrangement of substituents. The cyclohexyl rings feature the most protecting conformation for the electron-deficient carbon center. As always observed, when comparing the geometric parameters of NHCs and those of their $\mathrm{NHC}(\mathrm{H}+)$ precursors, the $\mathrm{N} 2-\mathrm{C} 1-\mathrm{N} 3$ angle for carbene $\mathbf{5 c}\left(114.5^{\circ}\right)$ is more acute than that for cation $4 \mathbf{c}\left(122.8^{\circ}\right)$. For the cation $4 \mathbf{c}$, the rather short endocyclic $\mathrm{N}-\mathrm{C}$ distances (1.33 and $1.32 \AA$ ) and the somewhat longer N2-B1 and N3-B2 bond distances (1.46 and $1.47 \AA$ ) compared to those of B1-N1 and B2-N1 (1.42 and $1.43 \AA$ ) suggest that the nitrogen lone pairs interact primarily with the carbon center. Indeed, in borazines, B$\mathrm{N}$ distances are in the range of $1.42-1.44 \AA .16$ In other words, the six $\pi$-electrons are divided into two separated allyl moieties: a cationic four $\pi$-electron NCN and a neutral four $\pi$-electron BNB system. In contrast, carbene 5c exhibits five B-N bond lengths, which are about equal

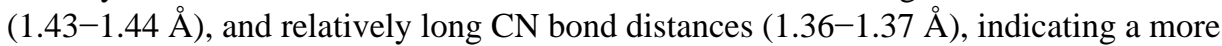
delocalized $\pi$-system.

To test the coordination ability of derivatives $\mathbf{5}$, carbene $\mathbf{5} \mathbf{c}$ was treated at $-78{ }^{\circ} \mathrm{C}$ with half an equivalent of bis( $\mu$-chlorocyclooctadienerhodium). After workup, complex $\mathbf{6 c}$ was isolated as highly thermally stable single crystals. Not surprisingly, the value of the $\mathrm{C}_{\text {carbene }}-\mathrm{Rh}$ bond length for $\mathbf{6 c}(2.05 \AA)$ is within the typical range for analogous complexes bearing classical NHC ligands A-D $(2.00-2.06 \AA) .{ }^{17}$ To compare the electron-donating ability of carbenes $\mathbf{5 a}-\mathbf{c}$, the corresponding $c i s-\left[\mathrm{RhCl}(\mathrm{CO})_{2}(\mathbf{5})\right]$ complexes $\mathbf{7 a}-\mathbf{c}$ were prepared by treatment of $\mathbf{6 c}$ with $\mathrm{CO}$ at room temperature, or alternatively by addition of carbenes $\mathbf{5 a}-\mathbf{c}$ to half an equivalent of bis( $\mu$-chlorodicarbonylrhodium). The average value of the carbonyl stretching frequencies $\left[v_{\mathrm{av}}(\mathrm{CO}): 2029(\mathbf{7 a}), 2033(\mathbf{7 b}), 2038(7 \mathbf{c}), \mathrm{cm}^{-1}\right]$ clearly indicate that the donor power of carbenes 7 decreases in the order $7 \mathbf{a}>\mathbf{7 b}>\mathbf{7 c}$, following the donor ability of the boron substituents. It is important to note that (i) a difference of only $3 \mathrm{~cm}^{-1}$ was observed between the $v_{\text {av }}(\mathrm{CO})$ values of saturated $\mathbf{A}$ (2038) and unsaturated $\mathbf{B}$ (2041) NHCs; (ii) the donor power of $\mathbf{7 a}$ and $\mathbf{7 b}$ seems to be higher than those of $\mathbf{A}$ and $\mathbf{B}$, which is in agreement with the higher electropositivity of boron compared to that of carbon.

In conclusion, carbene analogues of borazines are readily available as highly thermally stable species [mp $176{ }^{\circ} \mathrm{C}$ without decomposition (7c)]. They give rise to stable transition metal complexes. Importantly, their electronic properties can readily be tuned by varying the nature of the boron substituents. Their efficiency as organic catalysts and as ligands for transition metal catalysts is currently under investigation.

\section{Acknowledgment}

We are grateful to RHODIA and the NIH (R01 GM 68825) for financial support of this work, and to the Alexander von Humboldt Foundation (C.P.).

Full experimental and spectroscopic data for all new compounds, and X-ray crystallographic data for $\mathbf{4 c}, \mathbf{5 c}$, and $\mathbf{6 c}$ (CIF). This material is available free of charge via the Internet at http://pubs.acs.org.

\section{References}

1. Moss, RA.; Platz, MS.; Jones, M, Jr.. Reactive Intermediates Chemistry. Wiley; New York: 2004.

2. a Kirmse W. Angew. Chem., Int. Ed 2004;43:1767-1769.For reviews on stable singlet carbenes b Canac Y, Soleilhavoup M, Conejero S, Bertrand G. J. Organomet. Chem 2004;689:3857-3865. c Bourissou D, Guerret O, Gabbaï FP, Bertrand G. Chem. Rev 2000;100:39-92. [PubMed: 11749234] 
3. a Enders D, Balensiefer T. Acc. Chem. Res 2004;37:534-541. [PubMed: 15311952]For reviews on stable carbenes as organic catalysts b Johnson JS. Angew. Chem., Int. Ed 2004;43:1326-1328. c Nair V, Bindu S, Sreekumar V. Angew. Chem., Int. Ed 2004;43:5130-5135.

4. a Enders D, Gielen H. J. Organomet. Chem 2001;617-618:70-80.For reviews on stable carbenes as ligand for transition metal catalysts b Herrmann WA. Angew. Chem., Int. Ed 2002;41:1290-1309. c Perry MC, Burgess K. Tetrahedron: Asymmetry 2003;14:951-961. d Peris E, Crabtree RH. Coord. Chem. Rev 2004;248:2239-2246. e Crudden CM, Allen DP. Coord. Chem. Rev 2004;248:2247-2273. f César V, Bellemin-Laponnaz S, Gade LH. Chem. Soc. Rev 2004;33:619-636. [PubMed: 15592627] g Scott NM, Nolan SP. Eur. J. Inorg. Chem 2005:1815-1828.

5. Arduengo AJ III, Goerlich JR, Marshall WJA. J. Am. Chem. Soc 1995;117:11027-11028.

6. a Arduengo AJ III, Harlow RL, Kline M. J. Am. Chem. Soc 1991;113:361-363. b Enders D, Breuer K, Raabe G, Runsink J, Teles JH, Melder JP, Ebel K, Brode S. Angew. Chem., Int. Ed. Engl 1995;34:1021-1023.

7. a Alder RW, Blake ME, Bortolotti C, Bufali S, Butts CP, Linehan E, Oliva JM, Orpen AG, Quayle MJ. Chem. Commun 1999:241-242. b Bazinet R, Yap GPA, Richeson S. J. Am. Chem. Soc 2003;125:13314-13315. [PubMed: 14583000] c Despagnet-Ayoub E, Grubbs RH. J. Am. Chem. Soc 2004;126:10198-10199. [PubMed: 15315404] d Krahulic KE, Enright GD, Parvez M, Roeseler R. J. Am. Chem. Soc 2005;127:4142-4143. [PubMed: 15783175]

8. a Alder RW, Allen PR, Murray M, Orpen AG. Angew. Chem., Int. Ed. Engl 1996;35:1121-1123. b Alder RW, Blake ME, Chaker L, Harvey JN, Paolini F, Schutz J. Angew. Chem., Int. Ed 2004;43:5896-5911.

9. Herrmann WA, Ofele K, Preysing v. D. Herdtweck E. J. Organomet. Chem 2003;684:235-248.

10. Stock A, Pohland E. Chem. Ber 1926;59:2215-2223.

11. a Corso M, Auwärter W, Muntwiler M, Tamai A, Greber T, Osterwalder J. Science 2004;303:217220. [PubMed: 14716010] b Jeon J-K, Uchimaru Y, Kim D-P. Inorg. Chem 2004;43:4796-4798. [PubMed: 15285647]

12. a Phukan AK, Kalagi RP, Gadre SR, Jemmis ED. Inorg. Chem 2004;43:5824-5832. [PubMed: 15360231] b Timoshkin AY, Frenking G. Inorg. Chem 2003;42:60-69. [PubMed: 12513078]

13. Selected spectroscopic data: ${ }^{13} \mathrm{C}\left\{{ }^{1} \mathrm{H}\right\} \delta 165.0$ (4a), 165.0 (4b), 163.6 (4c), 282.9 (5a), 281.5 (5b), $281.6(\mathbf{5 c}), 242.1(J=47.4 \mathrm{~Hz})(\mathbf{6 c}), 242.1(J=47.4 \mathrm{~Hz})(\mathbf{7 a}), 223.1(J=38.2 \mathrm{~Hz})(\mathbf{7 b}), 224.3(J=$ $38.6 \mathrm{~Hz})(\mathbf{7 c}),[\mathrm{NCN}] ;{ }^{11} \mathrm{~B}\left\{{ }^{1} \mathrm{H}\right\} \delta 25(\mathbf{4 a}), 26$ and $33(\mathbf{4 b}), 35(\mathbf{4 c}), 24(\mathbf{5 a}), 24$ and $31(\mathbf{5 b}), 31(\mathbf{5 c})$, 32 (6c), 24 (7a), 25 and 32 (7b), 30 (7c); IR $\left(\mathrm{CH}_{2} \mathrm{Cl}_{2}\right) \vee 2069$ and 1989 (7a), 2073 and 1994 (7b), 2077 and $2000(7 \mathrm{c}) \mathrm{cm}^{-1}[v(\mathrm{CO})]$.

14. Chivers T, Fedorchuk C, Parvez M. Inorg. Chem 2004;43:2643-2653. [PubMed: 15074983]

15. Crystallographic data (excluding structure factors) have been deposited with the Cambridge Crystallographic Data Centre as supplementary publication Nos. CCDC-271071 (4c), 271072 (5c), and 271073 (6c). Copies of the data can be obtained free of charge on application to CCDC, 12 Union Road, Cambridge CB2 1 EZ, UK [fax: (+44)1223-336-033; email: deposit@ccdc.cam.ac.uk]

16. a Jaska CA, Temple K, Lough AJ, Manners I. J. Am. Chem. Soc 2003;125:9424-9434. [PubMed: 12889973] b Jäschke T, Jansen M. Z. Anorg. Allg. Chem 2004;630:239-243.

17. a Denk K, Sirsch P, Herrmann WA. J. Organomet. Chem 2002;649:219-224. b Herrmann WA, Ofële K, Preysing D. v. Herdtweck E. J. Organomet. Chem 2003;684:235-248. c Coleman AW, Hitchcock PB, Lappert MF, Maskell RK, Müller JH. J. Organomet. Chem 1985;296:173-196. d Herrmann WA, Elison M, Fischer J, Köcher C, Artus GRJ. Chem.-Eur. J 1996;2:772-780. e Enders D, Gielen H, Runsink J, Breuer K, Brode S, Boehn K. Eur. J. Inorg. Chem 1998:913-919. 


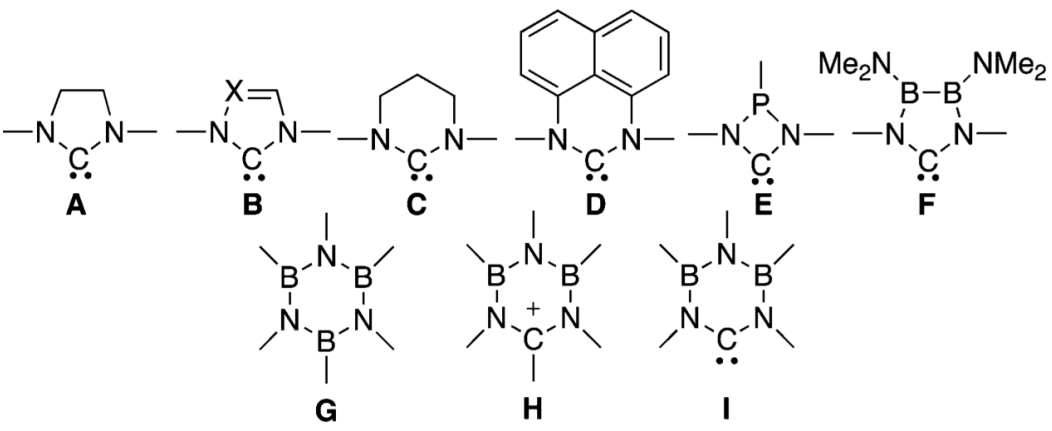

Scheme 1. 


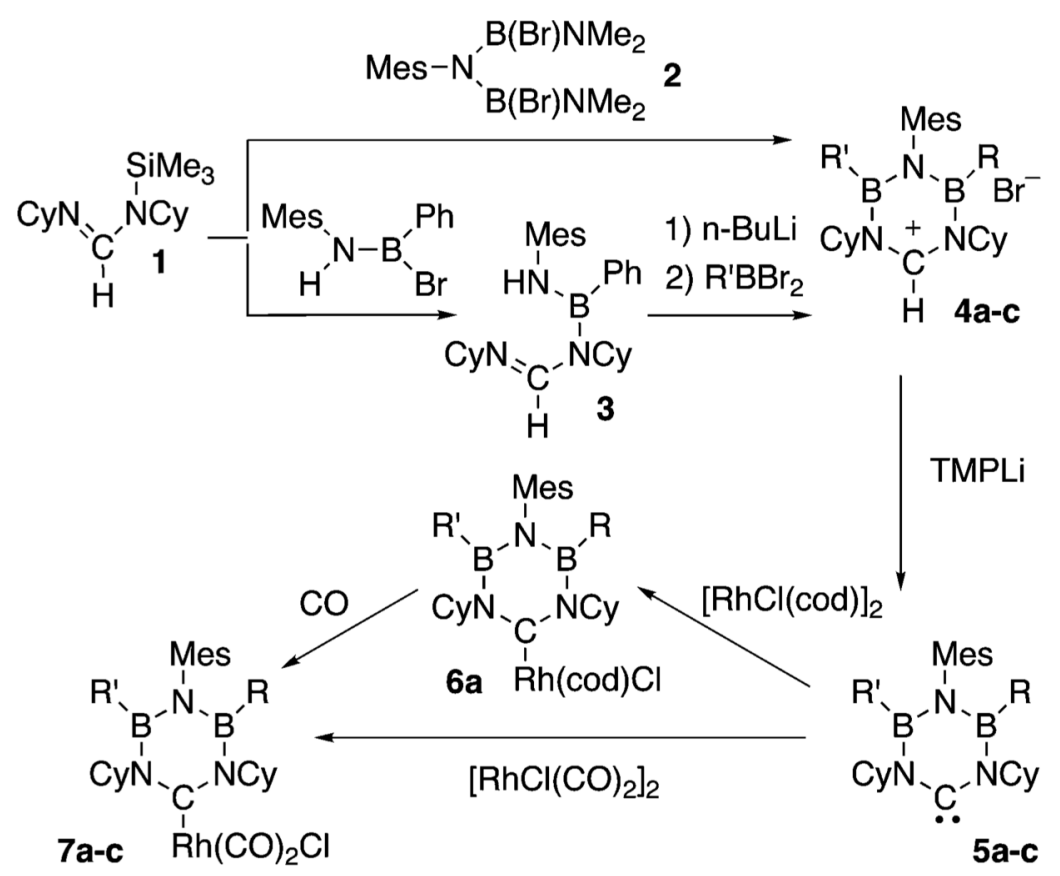

4a-7a: $R=\mathrm{R}^{\prime}=\mathrm{NMe}_{2} ;$ 4b-7b: $\mathrm{R}=\mathrm{Ph}, \mathrm{R}^{\prime}=\mathrm{NMe}_{2} ; \mathbf{4 c - 7 c}: \mathrm{R}=\mathrm{R}^{\prime}=\mathrm{Ph}$

Scheme 2. 

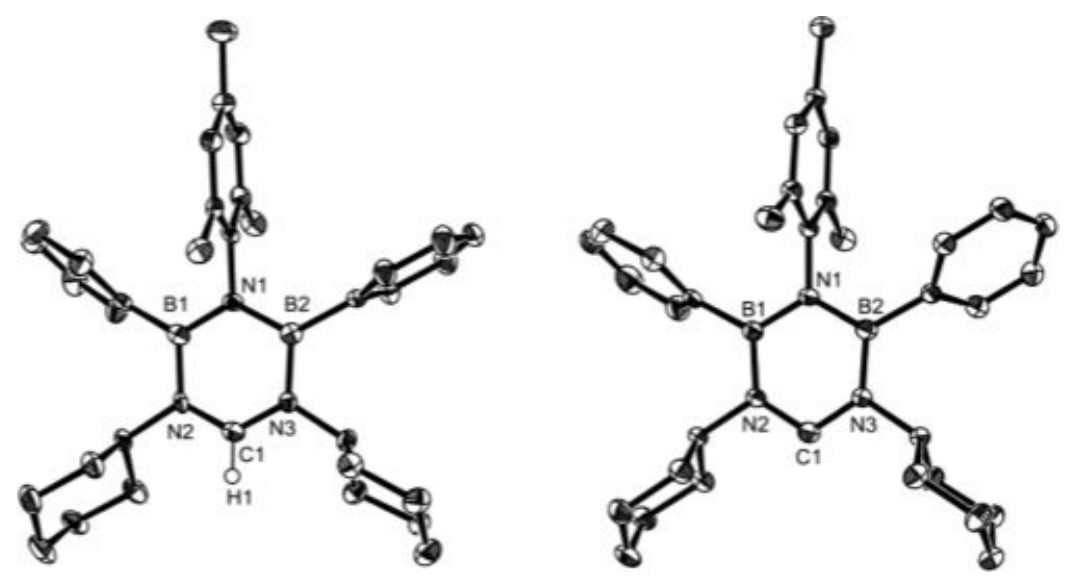

Figure 1.

Thermal ellipsoid diagram (50\% probability) of $\mathbf{4 c}$ (left) and $\mathbf{5 c}$ (right) (H atoms are omitted). Selected bond distances $(\AA)$ and angles $\left({ }^{\circ}\right)$ : 4c C1-N2 1.323(4), C1-N3 1.328(4), N2-B1 1.467 (4), N3-B2 1.460-(4), B1-N1 1.428(5), B2-N1 1.422(5), N2-C1-N3 122.8(3); 5c C1-N2 1.3664(18), C1-N3 1.3634(18), N2-B1 1.4442(19), N3-B2 1.4449-(19), B1-N1 1.4278(19), B2-N1 1.4356(19), N2-C1-N3 114.45(12). 